\title{
Los mecanismos léxico- sintácticos en el español de España: un estudio de casos
}

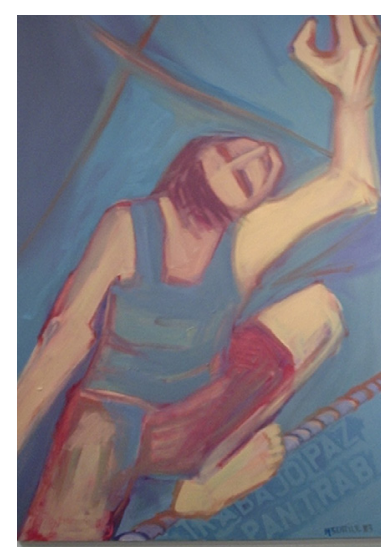

Miriam Pérez Pérez

Universidad de Valladolid, España

mpp_51@hotmail.com

Trabajo recibido el 24 de abril de 2018 y aprobado el 12 de octubre de 2018.

\begin{abstract}
Resumen
Las relaciones entre el léxico y la semántica son aún un campo lingüístico relativamente poco estudiado en comparación con otros campos, si bien, las investigaciones en este ámbito suelen limitarse a elementos muy concretos como pueden ser las metáforas o la semántica fraseológica. En las últimas décadas, comienza a surgir un especial interés por el impacto que tiene el léxico en relación con el sintagma concreto en el que se encuadra, ya que toda palabra emitida causa en el receptor una determinada interpretación de manera involuntaria e instantánea y de eso depende, en gran parte, el éxito o fracaso en el acto comunicativo. Esta investigación tiene como objetivo principal dar explicación a ciertos fenómenos que se producen en la interfaz léxico-sintáctica de los ejemplos seleccionados, basándonos, para ello, en las teorías más destacadas dentro de esta especialidad lingüística.
\end{abstract}

\section{The lexical-syntactic mechanisms in the Spanish of Spain: A study of cases}

\begin{abstract}
The relations between lexicon and semantics are still a linguistic field relatively unexplored in comparison with other fields, even though the researches in this sphere are usually limited to very specific elements, such as the metaphors or the phraseological semantics. In recent decades, it begins to emerge a special interest in the impact that the lexicon has in relation with the particular syntagm in which it forms part of. That is considering that every uttered word causes a certain interpretation in the receiver (in an involuntary and instantaneous way) and the success or failure during the communicative act depends, to a great extent, on it. This research has one principal aim which is to give an explanation to certain phenomena that are produced in the lexical-syntactic interface of the selected examples, based, for this, on the most important theories within this linguistic specialty.
\end{abstract}

\section{Palabras clave \\ léxico semántica acto comunicativo} fenómenos

\section{Keywords}

lexicon semantics communicative act phenomena 


\section{Os mecanismos léxico-sintáticos no espanhol da Espanha: Um estudo de casos}

\section{Resumo}

As relações entre o léxico e a semântica ainda são um campo linguístico relativamente pouco estudado em comparação com os outros campos, embora as pesquisas neste âmbito tendem a se limitar a elementos muito concretos como podem ser as metáforas ou a semântica fraseológica. Nas últimas décadas, começa a surgir um especial interesse pelo impacto que tem o léxico em relação ao sintagma concreto no qual é enquadrado, já que toda a palavra emitida causa no receptor uma determinada interpretação de maneira involuntária e instantânea e disso depende, em grande parte, o sucesso ou fracasso no ato comunicativo. Esta pesquisa tem como objetivo principal dar explicação a certos fenômenos que são produzidos na interface léxico-sintática dos exemplos selecionados, baseando-nos, para isto, nas teorias mais destacadas dentro desta especialidade linguística.

\section{Introducción}

Hace ya muchos años, se abandonó la idea clásica de que la lengua poseía una interpretación diáfana, sin adornos, donde el mensaje del emisor era interpretado por el receptor de manera unívoca. Poco a poco, fueron surgiendo estudios en torno al léxico y a la semántica, fruto de una reflexión que hacía pensar que no toda aquella palabra emitida (de manera oral o escrita) tiene un único análisis ni una única forma de realización a nivel sintáctico sino que la combinación diferente de palabras da lugar a interpretaciones diferentes. Así, nace el interés por determinar qué sucede en la interfaz léxico-sintaxis y, con ello, surgen dos corrientes que podrían considerarse, en cierta manera, complementarias: corriente lexicista y corriente sintactista. Tanto lexicistas como sintactistas justifican comportamientos diversos en relación con la proyección sintáctica de las propiedades léxicas de las entradas. Mientras los lexicistas aceptan que la formación y la derivación de palabras se produce en un estadio presintáctico y que la posición de las palabras se explica por su propia naturaleza léxica, los sintactistas defienden la proyección de las propiedades esenciales del léxico únicamente desde su estructura sintáctica, explicadas desde las relaciones que se crean entre las palabras.

Este trabajo, de carácter principalmente explicativo-descriptivo de fenómenos más que puramente teórico, tiene como objetivo principal el análisis detallado de ejemplos fundamentados en las siguientes construcciones:

1. La legitimación -o no legitimación- del se sin reservas en los ejemplos seleccionados, teniendo en cuenta la estructura eventiva y la relación léxico-sintaxis.

2. La selección del auxiliar en tiempos compuestos para verbos ergativos e inergativos en lenguas como el italiano, por ejemplo.

3. Descripción de las alternancias argumentales con respecto a la relación entre léxico y la sintaxis.

Palavras-chave

léxico semântica ato comunicativo fenômenos 
4. Análisis de oraciones derivadas partiendo de la hipótesis lexicista de RappaportHovav y Levin y de la representación léxico-semántica basada en la Regla de Expansión de Plantillas (Template Augmentation).

5. Alternancia transitiva directa/oblicua del verbo pensar y su estructura léxico relacional.

6. Oraciones que presentan verbo transitivo y se, ¿contienen el mismo predicado?

7. Construcción estar + gerundio en relación con los contextos oracionales, ¿qué propiedades consideramos que son competencia del léxico y cuáles serían los aspectos semánticos inducidos por la sintaxis teniendo en cuenta, entre otras, las propiedades del tipo predicado de individuo y predicado de estadio?

8. Fenómenos de gramaticalidad/agramaticalidad y/o aceptabilidad/inaceptabilidad teniendo en cuenta los siguientes aspectos: distinción entre predicado de individuo y predicado de estadio, categoría de aspecto léxico, rasgos de agentividad y control, factores de coacción aspectual, etcétera.

\section{Breve recorrido teórico en torno a los estudios léxico-sintácticos}

De acuerdo con la Teoría del Lexicón Generativo -TLG—, Pustejovsky (1995) defiende la idea de que el léxico no forma un conjunto cerrado e impermeable, sino que las entradas léxicas se combinan de manera creativa mediante ciertos mecanismos que explicarían las distintas apreciaciones semánticas que experimentan las palabras dependiendo del contexto en el que aparezcan. Dicho en otras palabras, si cambiamos el contexto donde hace su aparición una palabra, el significado puede variar. Se debe matizar aquí que no todas las combinaciones son posibles sino que debe estar dentro de las posibilidades léxicas de la propia entrada. Esto es lo que Pustejovsky (1995) denominó entrada léxica infraespecificada (o subléxica), es decir, cada ítem se considera parte de un conjunto más amplio que explicaría todas sus posibles combinaciones (polisemia lingüística). Según Pustejovsky (1995), los tipos de eventos son tres:

1. Estado: eventos sin dinamismo que tienen duración pero no un final.

2. Procesos: se oponen a los anteriores en que estos sí que son dinámicos (tienen duración y carecen de final).

3. Transiciones: al igual que los procesos, son dinámicos pero estos sí que tienen final.

4. La Estructura de Tipificación Léxica explica la relación existente entre las palabras que se encuentran en nuestro lexicón mental (los vínculos que establecen las palabras entre sí están relacionados con la información que contiene su Estructura de Qualia).

Por lo que respecta a la Estructura de Qualia definida por Pustejovsky (1995), que defiende la idea de que la definición de las palabras que conforman el lexicón contendría información fundamental (quale) acerca de la entidad aludida, esta información puede ser de cuatro tipos:

1. Quale constitutivo: pone de manifiesto la relación objeto-partes constituyentes (o bien la relación objeto-entidad de la que es parte).

2. Quale formal: nos aporta información sobre la forma, color, dimensión, etcétera del objeto. 
3. Quale télico: codifica el propósito/función del objeto.

4. Quale agentivo: muestra información del ente que desencadena el hecho que se predica.

Por otro lado, la teoría semantista de Jackendoff (1987 y 1990) aboga por un planteamiento en donde el léxico funcionaría como un elemento autónomo, con sus propias reglas, y que interacciona con la sintaxis. Jackendoff rechaza el carácter primitivo de los papeles temáticos (papel- $\theta$ ), sosteniendo en su lugar los argumentos como variables cuyo criterio temático no influye a nivel sintáctico y abogando, sin embargo, por categorías conceptuales: Cosa, Evento, Estado, Acción, Lugar, Trayectoria, Propiedad y Cantidad.

Por su parte, Hale y Keyser (1986 y 1993) sostienen que el significado interviene, determinantemente, en la forma sintáctica en la que se representa una oración dado que determina estructuras jerárquicas basadas en unidades sintácticas básicas y derivadas, es decir, la estructura sintáctica es la representación de la estructura argumental (véanse el Principio de Proyección Extendido y el Principio del Eslabón Mínimo). Defienden que la estructura superficial es la que adjudica los papeles temáticos, en otras palabras, según la posición del sintagma dentro de la oración, así será su papel temático y no al revés, el papel temático no se proyecta en tal o cual posición por el mero hecho de tener cierto papel.

Según la Hipótesis Lexicista (Rappaport Hovav y Levin 2002), los diversos contextos en los que puede presentarse un predicado verbal figuran en su entrada léxica. Los verbos alternantes (ejemplo, pensar) se analizarían como verbos polisémicos y su dificultad de procesamiento se supone mayor que en el caso de verbos no alternantes. Sin embargo, la Hipótesis Sintactista tiene en cuenta que las unidades léxicas, a priori, deberían poder manifestarse en cualquier estructura sintáctica.

En el siguiente apartado (Los mecanismos léxico-sintácticos: un estudio de casos), el lector observará las correspondientes interpretaciones que hemos considerado oportunas para defender las relaciones léxico-sintácticas que se muestran en los ejemplos seleccionados. Para ello, ampliaremos las bases tanto teóricas aquí expuestas como prácticas aún por descubrir en las próximas páginas.

\section{Los mecanismos léxico-sintácticos: un estudio de casos}

En este apartado, el lector podrá encontrar recopilados una serie de ejemplos tomados de la vida cotidiana, oraciones "estas u otras similares" que todos oímos a menudo y que hallan en esta investigación una explicación lingüística técnica en la que se razona el porqué de los fenómenos aquí escogidos, tanto para aquellos que resultan gramaticales como para aquellos agramaticales o de dudosa gramaticalidad/aceptabilidad.

\subsection{El clítico se}

¿Por qué verbos como los que aparecen en las construcciones de (1) legitiman el clítico se sin reservas, frente a los de (2)? ¿Por qué los de (3) no pueden admitir $s e$ ? 
(1) Se ha quemado la tortilla.

Se ha agravado la situación.

(2) (Se) murió (repentinamente).

(Se) enfermó (repentinamente).

(3) *Se ardió el bosque.

*María se palideció.

Primeramente, intentaremos dar una respuesta teniendo en cuenta la estructura eventiva y la relación léxico-sintaxis. En los ejemplos de (1), encontramos un se medio. Decimos que es un se medio porque designa "la entidad que es afectada por el predicado o experimenta el proceso expresado por él con la participación necesaria de un agente externo que lo active" (Bosque y Gutiérrez-Rexach 2011,420). Ese se es característico de la tercera persona. En ambos casos (1), estaríamos ante construcciones anticausativas (verbos de cambio de estado):

(1) Se ha quemado la tortilla (variante con se; el objeto se eleva a la posición de sujeto) versus (1a) El fuego quemó la tortilla (variante transitiva cuyo sujeto exterioriza la causa del predicado).

Se ha agravado la situación (variante con se; el objeto se eleva a la posición de sujeto) versus (1b) La crisis ha agravado la situación (variante transitiva cuyo sujeto exterioriza la causa del predicado).

En los ejemplos de (2), estamos ante los verbos anticausativos morir y enfermar con la posible aparición de un se aspectual (o un se medio según defiende García Fernández $(2011,11)$ ). Verbos como morir son considerados "predicados télicos" pues se pueden combinar con sintagmas preposicionales temporales de duración introducidos por en: Murió en un momento, sin sufrimiento. Sin embargo, enfermar acepta más fácilmente complementos introducidos por durante, no excluyendo los introducidos por en, diferencia que estriba en la posibilidad de telicidad o atelicidad del predicado: Enfermó durante la segunda Guerra Mundial/Enfermó en verano (García Fernández 2011). En ambos verbos observamos un logro (la muerte/la enfermedad) seguido de un estado (estar muerto/estar enfermo). Investigadores como Fernández García, Sánchez López, Bello y un largo etcétera han escrito a menudo artículos que versan sobre la aparición o ausencia del se en este tipo de construcciones. Según Sánchez López (2002, 108), el uso de ese se es facultativo, de lo que se deduce la inexistencia de un cambio sustancial entre la construcción con se o sin él. Por su parte, Bello (1981) defiende la idea de que la presencia de se marca el proceso que lleva al cambio de estado, por tanto, si no existe un marcado proceso durativo, el se se suele omitir, como es el caso que nos atañe en (2). Varios son los autores que consideran que el verbo morir "aquel utilizado en titulares de periódicos, en enciclopedias, etc.” es un verbo que denota más formalidad que morirse, usado en ambientes más familiares (2a y 2 b):

(2a) El Papa ha muerto (frente a El Papa se ha muerto).

(2b) Se ha muerto mi hermana (frente a Ha muerto mi hermana). 
Asimismo, se ha mencionado en varias ocasiones que en oraciones como la que se nos presenta en (2a), el se indica que la muerte ha sido un proceso natural (no provocado por una causa externa) y, en este caso, el sujeto sería experimentante y no paciente (García Fernández 2011). García Fernández (2011) defiende que el se en este tipo de oraciones no es un se aspectual pues no pueden equipararse tales construcciones a comer la tortilla/comerse la tortilla "en este último caso, estaríamos ante una realización marcada por ese clítico".

Por tanto, y resumiendo, morir y morirse son dos verbos del mismo campo semántico pero con ciertos matices. Por ello, no debemos pensar que el segundo es el primero con un clítico anexionado (buena prueba de ello es la existencia, en lenguas romances como el francés o el italiano, de dos items léxicos diferentes para cada pareja de verbos: s'endormir/addormentarsi).

En los ejemplos de (3), tanto arder como palidecer (cambio de estado de causa interna) son verbos inacusativos (ergativos). No poseen un sujeto gramatical agente; poseen un "objeto profundo" asimilable al sujeto paciente de las gramáticas tradicionales, cuyo papel temático - papel $\theta-$ es el de tema o paciente. Según Mendikoetxea (2000), estos verbos tienen una serie de características que los distinguen de los verbos de causa externa:

1. No participan en la alternancia causativa: "El fuego ardió el bosque.

2. No admiten el adjunto por sí solo/por sí mismo: "El bosque ardió por sí mismo.

3. Restringen el tipo de sujetos de los que se predica algo: *El coche palideció.

Este tipo de verbos (denominados "de cambio de estado" como palidecer, envejecer, enrojecer, ensordecer, etc.), que expresan eventualidades de causa interna, no admiten el pronombre se: *se palideció, *se envejeció, *se enrojeció, *se ensordeció, etcétera.

\subsection{Verbos ergativos versus verbos inergativos}

¿Considera el lector que los ejemplos anteriores confirman la consideración de que la diferencia entre verbos ergativos e inergativos es de naturaleza léxica y se refleja en la sintaxis mediante diferentes procedimientos como es el caso de la selección del verbo auxiliar en los tiempos compuestos en idiomas como el italiano o el neerlandés? (En italiano, se usa el auxiliar essere con inacusativos, y avere con inergativos.) Observe las siguientes oraciones:

(4) Gianni ha corso.

(5) Gianni è corso a casa.

Ante una misma entrada léxica (correre denota léxicamente una actividad), podemos encontrarnos diferente combinatoria de constituyentes (complementos), es decir, construcciones donde el aspecto léxico no especifica qué estructura elegir pero, en cambio, sí que interviene en las restricciones de la combinatoria de sintagmas. Dependiendo de la eventualidad descrita por el verbo (asociada a una actividad o a una realización, que se derivará de su matiz aspectual léxico), se le adjudicará al verbo unos u otros argumentos. Tanto actividades como realizaciones comparten la idea de proceso, algo que no experimentan los logros (Bosque y Gutiérrez-Rexach 2011). 
En la oración (4), estaríamos ante una estructura sintáctica con marcado rasgo atélico en la que no se manifiesta el objeto nocional del verbo correre (decimos objeto nocional por la similitud existente con los objetos directos, presentes en los verbos transitivos, algo que deja fuera a los inacusativos) pero que permanece oculto "el auxiliar avere también se utiliza con verbos transitivos". Podríamos decir Gianni ha corso la maratona benefica contro il cancro, y, en este caso, catalizaríamos el constituyente oculto que poseen los verbos inergativos por lo que estaría justificado el uso del auxiliar avere con el uso inergativo de correre en la primera construcción.

En la oración (5), se nos presenta un evento (realización) expresado con el mismo verbo pero ante una construcción inacusativa, en la que se observa un sujeto agente y un evento de moción "movimiento realizado hacia un lugar final o meta" (a casa nos informa no solo de la trayectoria seguida sino la culminación del evento). La coerción ejercida por el modificador (sintagma preposicional a casa) delimita la eventualidad en el tiempo (telicidad). La existencia del modificador eventivo "también denominado término o meta" (a casa) coacciona al predicado y hace que adquiera la telicidad "la delimitación" de la que carece. Por tanto, ante un verbo inacustivo que designa una trayectoria cuyo fin está explícito, el uso de essere está totalmente justificado.

Según Amaya Mendikoetxea (2009), hay verbos que son considerados típicamente inergativos pero que ante la presencia de un sintagma preposicional de dirección actúan como un verbo inacusativo, es decir, seleccionan el verbo essere (ser) y mostrarían ciertas propiedades específicas de esos verbos.

Sorace (2000) afirma que existe cierta variación en la elección del auxiliar con verbos intransitivos. Existiría, pues, una gradación jerárquica cuyos extremos estarían formados, por un lado, por verbos plenamente inacusativos, que seleccionan el auxiliar essere y, por otro, por verbos inergativos, que seleccionan el auxiliar avere. Según su hipótesis, entre medias encontraríamos una amplia variedad de verbos que no se aproximan tanto a los prototípicos y actuarían, unas veces, con avere y, otras, con essere.

Para finalizar, mencionar, también, algo que puede ser equiparable a lo que muestran los ejemplos de esta pregunta: la existencia de construcciones semejantes en el español antiguo hasta los primeros años del siglo XVII, donde la alternancia de auxiliares deja de ser verdaderamente relevante para dar paso a las construcciones de tiempos compuestos únicamente con el verbo haber. Hasta este siglo, las alternancias entre ser y haber en los tiempos compuestos funcionaban de igual modo que lo hacen hoy en día en italiano (los ejemplos han sido adaptados a sus equivalentes en el español actual):

El Rey es corrido hasta el castillo / El Rey ha visto a su hija.

Más ejemplos como estos los encontramos en el francés actual: 


\subsection{Alternancias argumentales}

Examine ahora las alternancias argumentales en las siguientes oraciones. En alguno de los casos, ¿el verbo induce Coacción del Tipo de Complemento? ¿Hay un único verbo léxico empezar con realización argumental múltiple? ¿El verbo empezar tiene un comportamiento sintáctico análogo al del verbo comenzar? Observe, además, los sustantivos deverbales correspondientes.

(6) Todavía no ha empezado [el artículo/el trabajo].

(7) Ya ha empezado con el [artículo/trabajo].

(8) Ha empezado por el [artículo/trabajo] (cf. *Ya he empezado por [el artículo/ trabajo]).

(9) Empieza por decirle a María que tiene que entregar el trabajo mañana.

(10) *Empieza con decirle a María...

(11) Ha empezado a escribir el trabajo.

(12) Ha empezado por el postre.

De acuerdo con la Teoría del Lexicón Generativo (TLG) existen cuatro niveles de representación de la información y cuyo contenido está presente en las entradas léxicas (De Miguel 2009):

1. Estructura argumental (EA).

2. Estructura eventiva (EE).

3. Estructura de Qualia.

4. Estructura de Tipificación Léxica.

Cada una de las partes que acabamos de citar son las responsables de la interpretación semántica de una oración. Si nos fijamos en la EA, esta nos informa del número de argumentos de un predicado (y dónde se localizan sintácticamente) y la clase a la que pertenecen: [objeto], [individuo], etcétera. En cuanto a la EE, nos indica el tipo de evento expresado por un predicado.

Una vez expuesto lo anterior, y si nos ceñimos a los ejemplos dados, podemos explicar los fenómenos que en ellos se plantean. En el ejemplo (6), observamos que tanto artículo como trabajo comparten información codificada por su quale formal: ambos aluden a objetos "similares" que comparten características que les hacen pertenecer al "mismo" grupo (por ejemplo, objeto de papel que contiene información escrita). Como bien menciona De Miguel (2009), a partir de las investigaciones de Pustejovsky, "el verbo empezar selecciona semánticamente un evento en la posición de objeto [...] no admite, en principio, un nombre que no denote un evento [...] sin embargo, no es raro que pueda construirse de este último modo [...]". Pustejovsky sugiere, en este último caso, la existencia de una resemantización del sustantivo, que pasaría a expresar un evento - no manifiesto explícitamente como sucede en la oración (11) - y no un objeto como tal 
—véase el ejemplo con un sustantivo que denote un periodo (invierno) (Bosque 2016): Ya ha empezado el invierno / Ya ha comenzado el invierno-. Tal coacción es posible por la denominada definición infraespecificada que posibilita que el citado verbo posea un quale agentivo y un quale télico (el artículo/el trabajo). Por este motivo, la oración (6) es ambigua y pueden interpretarse dos eventos diferentes: empezar a leer la novela/el trabajo o bien empezar a escribir la novela/el trabajo.

En el ejemplo (7) sucede un caso similar al ocurrido en (6), pero en esta ocasión se produce una alternancia lícita de verbo+preposición en lugar de verbo+objeto directo.

En (8), la preposición por nos indica que dentro de una serie de elementos, el primero que ha seleccionado es el artículo/trabajo y no otros. Aquí, la interpretación también es ambigua pues lo primero que puede haber empezado a escribir es el artículo/trabajo o bien lo primero que puede haber empezado a leer es el artículo/trabajo. En este caso, observamos un evento dinámico, de duración indeterminada y sin final explícito, lo que lo convierte en un proceso, de ahí, que la oración *Ya he empezado por el artículo/trabajo resulte agramatical puesto que el adverbio ya dota de telicidad a la oración y es incompatible con la atelicidad mostrada en la segunda construcción (8).

Por otra parte, en (9) y (10) podemos observar similitudes y diferencias. Ambas están formuladas con el verbo empezar + preposición, también en (11). Sin embargo, (10) resulta agramatical, ¿̇por qué? Vamos a intentar dar una respuesta. El verbo empezar puede regir, en ciertos contextos, las preposiciones por y con, como ya hemos visto. No obstante, no pueden ser utilizadas ni arbitraria ni indiscriminadamente: solo si la definición infraespecificada del verbo que lo rige (hablamos en este caso concreto de empezar) permite la correcta interpretación de la palabra rectora. En este caso, parece ser que en (10) no lo permite. La preposición por legitima sintagmas nominales determinados a su derecha o bien, verbos, como es el caso de (9). Ahora bien, el caso de con es diferente: con solo rige a su derecha sintagmas nominales determinados, resultando agramatical la siguiente secuencia: verbo + con + verbo.

Por su parte, en (12) tan solo extraemos una única interpretación: $\mathrm{Ha}$ empezado por el postre sería sinónimo de Ha empezado a comer el postre, es decir, lo primero que ha comido es el postre, caso similar al observado en (8).

Nótese, en todos los casos expuestos, que los verbos empezar y comenzar son sinónimos "incluso cuando aparecen formando parte de perífrasis" y tienen un comportamiento sintáctico equiparable. Veamos los ejemplos que aparecen a continuación:

(6) Todavía no ha empezado el artículo versus (6a) Todavía no ha comenzado el artículo.

(7) Ya ha empezado con el trabajo versus (7a) Ya ha comenzado con el trabajo.

(9) Empieza por decirle a María que tiene que [...] versus (9a) *Comienza por decirle a María que tiene que [...].

(10) *Empieza con decirle a María [...] versus (10a)*Comienza con decirle a María [...]. 
Ya interpretadas las oraciones, podemos concluir que existe una diferenciación insuficiente de las palabras presentes en el léxico en relación con las situaciones sintácticas en las que pueden aparecer. Según la TLG, el lexicón mental se adapta al contexto en el que se manifiesta: "su activación está determinada por la información subléxica contenida en la EQ y en la EE de las palabras" (De Miguel 2009). Gracias a esto, podríamos explicar los fenómenos de polisemia sin tener la necesidad de incluir diferentes entradas léxicas para cada palabra. En palabras de la propia De Miguel (2009) "el hablante es capaz de generar sentidos no finitos haciendo uso de recursos finitos".

\subsection{Estructuras derivadas}

Ahora bien, ¿qué sucede en una lengua tan extendida $-\mathrm{y}$ no derivada del latín - como es el inglés? Veamos: según la estructura de (13), la interpretación de la oración (14) se consideraría derivada — se añade un subevento de Logro- en relación con la (15):

(13) $[\mathrm{x}$ ACT <sweep $>\mathrm{y}]$

(14) Terry swept the floor ('T. barrió el suelo').

(15) Terry swept ('T. barrió').

¿Se podría considerar a la inversa? ¿Qué consecuencias determinaría una respuesta afirmativa a esta cuestión para la hipótesis lexicista de Rappaport y Levin? $C f$. además, los datos de (16) y (17):

(16) Ana barrió (las) migas del suelo / Ana barrió el suelo de migas.

(17) Pepe limpió el polvo de la mesa / Pepe limpió de polvo la mesa.

Por otra parte, ¿diría usted que (19) deriva de (18)? ¿Se puede suprimir el subevento resultativo en una representación léxico-semántica basada en la Template Augmentation, la regla de expansión de plantillas?

(18) Ana barrió las migas del suelo (esta mañana).

(19) Ana barrió migas del suelo (esta mañana).

Según Mendikoetxea (2009), hay verbos que demuestran una flexibilidad mayor en su significado ("comportamiento inestable") que otros, que se muestran más rígidos. Tal es el caso del verbo de modo en inglés sweep ('barrer') que se muestra más flexible que otro tipo de verbos. En palabras de su autora, esta clase de verbos muestran una "polisemia regular" (Mendikoetxea 2009, 308). La polisemia regular fue definida por Apresjan (1973) del siguiente modo: son aquellos "verbos pertenecientes a las mismas clases semánticas que exhiben los mismos patrones de variación".

El verbo sweep puede aparecer en construcciones con objeto directo (14) o sin él (15) y también en construcciones eventivas donde "el tema cambia de lugar", como en (16) y (17). Los mecanismos de proyección vistos en los ejemplos reflejan esta polisemia sintáctica.

Los verbos, en español, se dividen en dos grandes grupos (no citamos aquí otras subcategorías): transitivos e intransitivos. Dentro de estos últimos, 
podemos diferenciar, de acuerdo con la Hipótesis de la Inacusatividad de Perlmutter (1978), dos tipos de verbos intransitivos: inacusativos (o ergativos) y los inergativos (o intransitivos puros). Según la hipótesis de Rappaport y Levin (2002), ambos tipos de verbos poseen entradas léxicas diferentes: mientras que los inergativos poseen un sujeto gramatical que controla la acción (agente), los inacusativos poseen su único argumento con la función semántica de tema.

Una vez expuesto lo anterior, podríamos decir que el verbo sweep ('barrer') es, en principio, un verbo transitivo y así se muestra en su entrada léxica -entendemos que cuando alguien (un sujeto agente) barre, siempre ha de barrer algo- . No obstante, su proyección en la sintaxis permite que el verbo se muestre sin su segunda valencia (objeto directo) y actúe como "intransitivo", en cuyo caso, pasa de designar una realización -Terry swept the floor- a designar una actividad - Terry swept-. Creemos que sería más correcto interpretar que la estructura primitiva es aquella que expresa una actividad y no aquella de realización (realización entendida como actividad+logro). Según Rappaport y Levin (2002), las actividades se pueden convertir en logros pero los logros no pueden convertirse en actividades, hipótesis que vendría a reforzar lo dicho hasta ahora.

En (16), explicación válida para la construcción (17), Ana barrió (las) migas del suelo, observamos una eventualidad en la que el tema "cambia de lugar", es decir, este ejemplo sería parafraseable por 'Ana barrió las migas que tenía el suelo' (mediante oración de relativo especificativa) o también 'Ana quitó las migas del suelo con la escoba -y desaparecieron de donde estaban antes-'. La segunda construcción de (16), se podría reproducir/parafrasear, en cierto modo, como 'Ana barrió el suelo, que tenía migas', es decir, existirían dos subeventos: por un lado, una realización y, por otro, un evento localizado en un lugar y un tiempo determinado (tener migas). A partir de esto, podemos establecer una diferencia entre (14) y (16)/(17): en (14), se advierte el uso transitivo de sweep, que se muestra como una realización. Sin embargo, en (16) y (17) observamos dos subeventos que se dan simultáneos en el tiempo y se simplifican mediante la preposición de. En (16) y (17), podemos ver, según explica Mendikoetxea $(2007,61)$, una alternancia en la realización sintáctica de los argumentos: bien en el caso de Ana barrió el suelo de migas o bien en el de Pepe limpió de polvo la mesa, se advierten sendas alternancias locativas de los argumentos 1 y 2, obteniéndose interpretaciones afines a Ana barrió (las) migas del suelo y Pepe limpió el polvo de la mesa respectivamente. Estaríamos, pues, ante un VTI - verbo de tema incremental en palabras de su autor, Dowty (1991) — que permite la inespecificación de sus objetos (caso similar al que encontramos en verbos como leer, comer, fregar, frotar, rascar, etcétera, que no necesitan explicitar el material, la locación o el objeto no subcategorizado de que se trate). En tales casos, observamos que el argumento (objeto directo) se muestra como un tema incremental, como en (20) y (21):

(20) Antonio comió/Antonio comió tortilla de patata.

(21) Antonio barrió/Antonio barrió el suelo/Antonio barrió (las) migas.

Para ser algo más precisos en este ámbito, sería recomendable decir que más que ante un verbo con tema incremental (VTI) estamos ante un verbo con potencial tema incremental (VPTI), especialmente característicos de "verbos de contacto de superficie" (Tenny 1992). Estos verbos permiten una doble lectura, atélica (22) y télica (23): 
(22) Antonio barrió el suelo durante horas. (atélica)

(23) Antonio barrió el suelo en dos horas. (télica)

En el caso (16), (las) migas en el primer caso y el suelo en el segundo actuarían como tema incremental (TI). En (17), sucedería lo mismo: el polvo sería el TI en el primer ejemplo de (17) y la mesa lo sería en el segundo ejemplo de (17), siendo todos ellos los objetos directos de sus respectivas oraciones. Como vemos, este tipo de verbos fomentan la alternancia de realización argumental; además, no imponen restricciones semánticas en sus cláusulas.

Según Mendikoetxea (2007, 79), "Las plantillas de estructuras de eventos se pueden expandir siempre que el resultado sea una plantilla posible del inventario de plantillas de estructuras de eventos", es decir, las expresiones derivadas se consiguen mediante la Regla de Expansión de Plantillas.

De ello se deduce que la diferencia entre la estructura primitiva y las derivadas que se observan en (16), (17), (18) y (19) son realizaciones que, a su vez, se analizan de la siguiente manera:

1. Ejemplos (16), (17) y (18). Cambio de lugar (interpretado como 'Las migas ya no están en el suelo' o bien ‘El polvo ya no está en la mesa’).

2. Ejemplo (19). En este caso también lo interpretaríamos como cambio de lugar aunque la ausencia del determinante la implica que hay una leve diferencia semántica: la aparición de la presupone que tanto el hablante como el oyente conocen la existencia de esas migas en el suelo.

Sin embargo, en (19), podríamos decir que la ausencia de la implica que el hablante está dando una información a su oyente, quien, en principio, desconoce la existencia de tales migas porque también desconoce el hecho que provoca que ese objeto "migas" aparezca ahí en un momento determinado "esta mañana". Veamos un ejemplo que aclare esta cuestión:

(19a) -Juan: "Ana barrió migas del suelo (esta mañana), así que sí que estuvieron los chicos cenando en casa ayer por la noche".

-Tomás: “Yo pensé que ya se habían marchado de viaje y que cenaban fuera...”.

Para Mendikoetxea $(2007,79)$, los usos no primitivos del verbo sweep son fruto de la suma de una actividad y un logro, lo que da lugar a una realización (bien sea de cambio de lugar, de estado o de creación):

$\left[\left[x \mathrm{ACT}_{\text {<MANNER }}\right]\right.$ CAUSE [BECOME [Y STATE]

Actividad Logro

Esto explicaría por qué verbos que expresan actividades en sus entradas léxicas/primitivas son más flexibles (como decíamos al principio de esta pregunta) que aquellos que manifiestan realizaciones en las mismas. Por esta razón, el verbo barrer (sweep) admite la forma Ana barrió mientras que verbos como romper no admiten tal construcción (*Ana rompió, "descartándose aquí la resemantización del verbo romper como finalizar una relación. Con este tipo de verbos ha de explicitarse obligatoriamente el objeto directo del verbo"). 


\subsection{Argumentos nulos}

Según Hale y Keyser (1993), el verbo pensar es de alternancia transitiva directa/oblicua, y su estructura léxico relacional (ELR) legitima un argumento nulo. ¿Habría que considerar que existe semejanza entre los ejemplos (24), (25), (26) y oraciones del tipo Pedro no ha comido hoy o María baila muy bien en lo que respecta al argumento nulo?

(24) María ha pensado una propuesta.

(25) María ha pensado en una propuesta.

(26) María ha pensado sobre una propuesta.

Verbos del tipo comer y bailar eligen objetos cognados en su entrada léxica. Si el objeto propiamente dicho no se menciona en la estructura sintáctica, el oyente interpreta de manera mental (e innata) que el elemento no manifiesto, y recuperable del contexto, posee ciertos rasgos y no otros, es decir, ante el verbo comer, se interpreta que el objeto que le sigue, aunque no se manifieste, está ahí, oculto, pero está y tiene el rasgo [+comestible]. Nótese en este punto que el hecho de que no se manifieste no implica su anulación. Lo mismo sucede en el caso de bailar, pero en este caso, los objetos que pueden ir anexados a este ítem poseen el rasgo [+bailable]. Por tanto, el hablante, utilizando su conocimiento extralingüístico del mundo, integrará en la posición de objeto (en caso de que fuese necesario manifestarlo) entidades de nuestra realidad que cumplan los citados rasgos semánticos y con los que mantenga, por tanto, una relación hipónima. Según Simoni (2005), "Los verbos de alternancia transitivo-preposicional comparten características esenciales con los verbos inergativos como dance o laugh [...] Pueden funcionar como intransitivos [...]". De acuerdo con dicha afirmación, la Real Academia de la Lengua (en línea) dicta lo siguiente: "Pensar en [...] es intransitivo y se construye con un complemento con en cuando significa 'evocar o recordar'”. Dado el caso, podemos encontrar verbos como pensar "y similares" en donde el objeto directo (OD) no se manifiesta pero sí aparece un sintagma preposicional (SP) que cubre sus funciones e imita la forma de tal objeto.

En cualquiera de los tres ejemplos, el verbo pensar es bivalente: requiere un sujeto (que recibe el papel temático de experimentante) y un OD (sintagma determinante (SD) que recibe el papel temático de tema: la propuesta) o bien, un SP, también con papel $\theta$ de tema —en las oraciones (25) y (26)—, en cuyo caso, dan lugar a una oración intransitiva.

Ahora, confronte las oraciones (27), (28) y (29): ¿̇e trata de casos de función intransitiva del verbo pensar? ¿Cuantifica el elemento de grado sobre el argumento nulo, como afirma Simoni (2005)? ¿Es comparable la construcción (29) a María sabe mucho de Física Cuántica? ¿Diríamos que saber/ saber de comparte ELR con pensar/pensar en?

(27) Pedro siempre piensa antes de actuar.

(28) Pedro piensa tanto que no toma decisiones.

(29) María piensa mucho en su futuro. 
¿Son análogas las construcciones (25), (28) y (29) a las siguientes, citadas por Simoni (2005)?

(30) Podemos prescindir bastante de los Estados Unidos.

(31) No quiso discrepar mucho de las palabras del gobernador.

En las construcciones (27), (28) y (29), vemos que el verbo pensar se presenta como intransitivo, lo que no quiere decir que no subyazca un objeto directo tras tales construcciones (el sujeto es el agente del núcleo de la predicación).

Con respecto al cuantificador, su verdadera función se ejerce sobre la actividad que predica el verbo pensar (no sobre el objeto nulo, como se defiende en el artículo de Simoni (2005)). Como bien expone Fernández Leborans (2011), los modificadores mucho, (un) poco, bastante, demasiado, etcétera, cuantifican cantidades inciertas. El objetivo de incluir un cuantificador en aquellos casos en los que modifica a un predicado verbal puede responder, al menos, a una de las siguientes cuatro interpretaciones:

1. Como argumento de cantidad, equivalente a 'muchas cosas'.

2. Con una interpretación 'intensiva', equivalente a un adverbio de grado/intensidad.

3. Con lectura equivalente a 'duración'.

4. Con lectura equivalente a 'frecuencia'.

Partiendo de esta clasificación de modificadores, podemos afirmar que lo que se cuantifica es la duración de la actividad en sí, por lo que sería equivalente a algo así: 'piensa durante tanto tiempo', 'dedica tanto/mucho tiempo a pensar'.

En el ejemplo (29), no existe objeto nulo pues el sintagma preposicional contiene un sintagma determinante al que se refiere el predicado pensar (en).

Según Simoni (2005), verbos como pensar y saber mantienen cierta correspondencia en lo que a su estructura léxico-relacional se refiere: ambos son susceptibles de ser utilizados en construcciones del tipo V + SP, como pensar (en)/saber (de).

Con respecto a la supuesta analogía existente entre las oraciones (25), (28) y (29) con (30) y (31) (Fernández Leborans 2014), diríamos que no se trata de oraciones semejantes por las razones siguientes: el verbo pensar es un predicado graduable bien en el sentido durativo (piensa durante mucho/bastante tiempo) o bien en sentido frecuentivo (piensa con mucha/bastante frecuencia). Sin embargo, los verbos prescindir y discrepar no son predicados graduables, es decir, o se discrepa o no se discrepa, pero no se puede discrepar parcialmente. Esta misma explicación es extrapolable al verbo prescindir. Además de esto, debemos destacar que tanto discrepar como prescindir solo pueden aparecer con un constituyente (SP) introducido por su correspondiente preposición (de), a diferencia de pensar, que puede regir predicados tanto con preposición (SP) como sin ella (OD): 
(32) *Prescindo el pan/Prescindo del pan.

(33) *Discrepo tu opinión/Discrepo de tu opinión.

(34) El Ministro piensa soluciones para resolverlo/El Ministro piensa en soluciones para resolverlo.

\subsection{Construcciones pronominales}

Las siguientes cuatro oraciones presentan verbo transitivo y se: ¿̇cree el lector que contienen el mismo predicado?

(35) Pedro se curó a sí mismo.

(36) Pedro se curó por sí mismo.

(37) La herida se curó por sí sola.

(38) Pedro se curó él solo.

En este caso, estamos ante cuatro predicados que designan un episodio (=estadio; P-E) del elemento [ \pm animado] del que se predica algo (verbo de cambio de estado). Expresan eventos en un espacio y un tiempo determinados (estado acotado), es decir, están sometidos a diferenciaciones aspectuales. Debemos comprender que curar manifiesta, por decirlo de algún modo, un estado resultante (estar curado). Se entiende que el sujeto oracional interviene como participante del evento enunciado por el verbo, cuyo rasgo es [+perfectivo], teniendo en cuenta un proceso previo que dura más o menos en el tiempo (indeterminado). Si analizamos estos cuatro predicados, podemos diferenciar dos tipos de eventualidades dentro de las cuatro enunciadas por Vendler (1967):

1. Por un lado, observamos que las oraciones (35) y (38) (causa externa) son transitivas, con una posible lectura que contiene, quizás, el rasgo [-durativo] con respecto a (36) y (37).

2. Por otro lado, pese a que el verbo curar se concibe como transitivo, en (36) y (37)-causa interna-nos encontramos ante oraciones intransitivas en palabras de Mendikoetxea (no desde el nuestro punto de vista).

Podríamos decir que la causa externa estaría relacionada con los predicados reflexivos, pero ¿̇hacen referencia a un mismo tipo de evento? ¿Poseen la misma estructura sintáctica? ¿Poseen la misma estructura semántica, "papeles temáticos", y una única estructura argumental?

Con respecto a estas oraciones, Mendikoetxea, basándose en lo defendido por Jackendoff y Hale, asume que en las piezas léxicas existen rasgos "primitivos" que son los que "dirigen" la sintaxis y la estructura argumental (Jackendoff 1983, Hale 1986).

Si atendemos al tipo de evento presentado en cada oración y, teniendo en cuenta que los cuatro predicados se formulan con el verbo curar(se), podríamos proponer dos tipos de eventualidades, estableciendo matices mínimos entre unas construcciones y otras: 
1. Por un lado, las oraciones (36) y (37) tenderían hacia una realización más gradual ya que entendemos que, en ambas, existen los rasgos [+durativo] [+télico], pero que se adquieren según pasa el tiempo (tema incremental).

2. Por otro lado, podríamos interpretar que los predicados de (35) y (38) se aproximan más a logros porque comparten los rasgos [-durativo] [+télico]. Para ello, podemos argumentar que si estuviésemos ante una oración del tipo Pedro se curó la herida a sí mismo (por ejemplo, utilizó un desinfectante y gasas en ese momento), veríamos que el tiempo que dura esa acción es menor que la que se nos presenta ante La herida se curó por sí sola (por ejemplo, con el paso del tiempo), dado que, en este segundo ejemplo, entendemos que la curación no es momentánea y que requiere un proceso más largo para llegar a conseguirse.

Es innegable que en (35) y (36) nos encontramos ante constituyentes con categorías sintácticas diferentes (a sí mismo/por sí mismo) y donde la pasiva es irrealizable, a no ser que se proceda al cambio del pronombre sí por el pronombre él (36).

Según Chierchia (1989), la construcción inacusativa no supone la ausencia del predicado causativo sino su reflexivización, pero también matiza que sin evento causativo no entiende por qué los sujetos de los predicados inacusativos pueden ser antecedente de por sí mismo/por sí sola. Nosotros defenderíamos, más bien, la idea de que el problema no radica en el SP que lo acompaña sino en la naturaleza del verbo, que no es en sí inacusativo sino un verbo transitivo que no se comporta de manera canónica tal y como lo concebimos normativamente. Mendikoetxea defiende que las interpretaciones reflexivas se basan en interpretar un mismo constituyente como tema y causa, algo con lo que no estamos de acuerdo, pues asignar dos papeles temáticos a un mismo constituyente parece contravenir la teoría de los papeles $\theta$.

En la oración transitiva (35), el sujeto (al que se le asignaría el papel temático de agente) efectúa la acción que denota el verbo curar. Este evento se lleva a cabo sobre un "paciente" (pronombre clítico se) que aparece duplicado con la forma a sí mismo (sintagma preposicional o SP). Por tanto, derivado de esta correferencia, el SP en (35) remite al sujeto de la oración. Por ello, podemos concluir que la primera oración es reflexiva.

En la oración (36), podríamos defender la idea de que "Pedro" (sujeto gramatical) no es la causa de se curó, pero tampoco es el agente del mismo, es decir, Pedro no interfiere en que el cambio de estado se lleve a cabo sino que experimenta un estado final (estar curado) sin mediar en ello [+espontáneo]. Asimismo, en (37) no existe agentividad por parte de la herida. Sin embargo, en (35) y (38), observamos que Pedro es el agente, el que hace que se lleve a cabo la "cura". En el caso (36), Reinhart (1997), Reinhart y Siloni (2004) y Chierchia (1989) dirían que ese se actuaría como un operador de reducción que permite pasar de una oración transitiva a una intransitiva. Desde nuestro punto de vista, no estamos de acuerdo en el proceso de reducción argumental, pues que un argumento no se explicite en la estructura superficial (sin manifestación fonética), no quiere decir que desaparezca; simplemente, está omitido o no resulta relevante en un determinado contexto, lo que no quiere decir que se reduzca la valencia del verbo. 
En cuanto a la estructura de (37), Mendikoetxea (2000) plantea que estamos ante un predicado inacusativo, sin carácter reflexivo. La herida recibiría el papel temático de tema y la causa sería por sí sola.

Por lo que respecta a la estructura de (38), nos encontramos ante una predicación secundaria (él solo) que correfiere y concuerda con el sujeto (Pedro). El SN podía ser permutado por a sí mismo con lo cual nos llevaría a pensar en una interpretación paralela a la que hemos mencionado para la oración (35), con lo cual, estaríamos ante una oración transitiva-reflexiva. El hecho de que no se mencione que se curó Pedro, no quiere decir que ese objeto (argumento interno) se esfume. Basta con catalizar un SN en posición de objeto (tema) para probar que no existe la inacusatividad de la que nos habla Mendikoetxea:

(39) Pedro se curó la herida/la ampolla/la hemorragia él solo.

Otra postura que se ha defendido es que ante verbos de esta naturaleza, las posiciones internas son ocupadas por los adjuntos, pero ya hemos demostrado que esto no es así pues su elisión no justifica la "etiqueta" colocada a este y a otros verbos de índole similar.

Por otro lado, ¿̇consideraría el lector que la interpretación asignable a cada una de estas oraciones es inducida léxicamente? Pues bien, los ítems léxicos no proyectan en las construcciones sintácticas todo el contenido informativo de su entrada léxica para su adecuada lectura/interpretación. A partir del contenido, y junto con la propia proyección en la sintaxis, cada pieza consigue la interpretación específica que requiere en el acto comunicativo para una correcta lectura. Como bien arguye Fernández Leborans (2014), "la reflexividad es un fenómeno sintáctico, no léxico" pues en la entrada léxica no existe nada que nos indique los rasgos [+transitivo], [+reflexivo] o similares. Si bien es cierto que la raíz del verbo (parte nocional) atrae ciertos clíticos o ciertas construcciones que manifiestan una correferencialidad (reflejas > reflexivas) a través de morfemas particulares, todo ello se ve revelado en el seno oracional.

\subsection{Perífrasis estar + gerundio}

A partir de la construcción estar + gerundio en relación con los contextos oracionales que se indican abajo y a modo de generalizaciones descriptivas, ¿qué propiedades considera el lector que son competencia del léxico y cuáles serían los aspectos semánticos inducidos por la sintaxis? Prestemos especial atención a las propiedades del tipo predicado de individuo (P-I)/ predicado de estadio (P-E) ¿Se establecen propiedades compartidas por todos los contextos en los que aparece la construcción estar + gerundio?

(40) Pedro [está teniendo dificultades/*está teniendo los ojos azules].

(41) Se está encontrando mal/*se está estando mal.

(42) La película está siendo [de gran interés/“de muchos indios].

(43) Le está haciendo falta un ordenador.

（44） *Está admirando cada vez más la pintura flamenca/Está admirando cada vez más a su profesor de piano. 
(45) Ese tipo de argumentaciones [ "está implicando más contradicciones/?está necesitando más verificaciones].

Veamos qué sucede con la perífrasis estar + gerundio en (40): Pedro está teniendo dificultades/*está teniendo los ojos azules. En el predicado Pedro está teniendo dificultades interpretamos que la perífrasis en su forma progresiva asegura que el evento se está produciendo en la actualidad, en el momento de la enunciación, y que se extiende de manera indeterminada más allá del momento actual. En este caso, estamos ante un predicado de estadio (P-E) localizado en un marco espacio-temporal concreto. Esta oración expresa un episodio en la vida del sujeto que está teniendo lugar "aquí y ahora" (existe un dinamismo en la acción).

En el ejemplo agramatical de (40), observamos que se le está dando un valor dinamizador a la perífrasis del que carece en este caso (este valor aparece cuando se combina con un predicado de estadio). Como bien expone García Fernández (2011), en numerosas ocasiones se ha dicho que la perífrasis no puede acompañar a verbos que indiquen estado. Ante tal afirmación, García Fernández realiza una salvedad: la perífrasis resulta compatible cuando no se predica una propiedad del sujeto, sino cuando lo que se predica es un evento. Veamos el siguiente ejemplo (extraído de García Fernández 2011, 266):

1. Juan es tonto. ("Ser tonto" se interpreta como estado/propiedad permanente del individuo.)

2. Juan está siendo tonto. (Dinamización: “ser tonto” se interpreta como 'evento’, no permanente.)

En estos ejemplos, la morfología flexiva es la que marca la diferencia de interpretación: ante la primera lectura, interpretamos una propiedad del individuo en cuestión mientras que, en la segunda, vemos que ser tonto tiene un valor transitorio y que se enmarca en un momento espacio-temporal no determinado y, por ello, no puede ser equiparable a un estado como en el caso de (40). La diferencia entre los predicados de individuo y los predicados de estadio reside en sus propiedades semántico-aspectuales. Para algunos autores, la diferencia entre unos predicados y otros se plasma en la estructura informativa: en los predicados de individuo, el tópico de la predicación es el propio individuo; sin embargo, en los predicados de estadio, el tópico es el evento (Uriagereka y Raposo 1995). Dado que los predicados de individuo se caracterizan por tener los rasgos [+durativo] y [-télico] no pueden ser nunca compatibles con una delimitación espaciotemporal, pues iría en contra de su naturaleza:

1. Emilio es inteligente. (Se predica una cualidad permanente del sujeto por lo que la perífrasis de gerundio, que sitúa el predicado en un momento concreto en el tiempo, no está permitida en este tipo de predicados porque iría en contra del estado permanente que predica una cualidad que posee el sujeto.)

2. "Emilio está siendo inteligente desde el mes pasado. (Rechaza especificaciones temporales.)

En la oración (41), Se está encontrando mal, la dinamización del estado encontrarse mal mediante la perífrasis estar + gerundio es posible, pasando, así, a entenderse como predicado que denota un evento dinámico (P-E). 
Por el contrario, *Se está estando mal no es posible, pues estar mal, como expone García Fernández $(2011,253)$, "la perífrasis no se combina con el auxiliar de progresivo [...], imposibilidad de que la perífrasis se combine con el auxiliar de la forma".

En el ejemplo (42), La película está siendo de gran interés, es un predicado de estadio (P-E) sujeto a la subjetividad del emisor del mensaje (podría considerarse también $L a$ película está siendo un fracaso). Sin embargo, en el ejemplo *La película está siendo de muchos indios, estamos ante un predicado de individuo (P-I) que expone una cualidad del sujeto (La película) y, como ya hemos repetido anteriormente, el carácter permanente que le otorga la cualidad que posee bloquea su aparición junto a la perífrasis progresiva.

En Le está haciendo falta un ordenador, estamos ante un P-E (hacer falta), cuya construcción en progresivo sitúa la acción en el momento presente.

En cuanto a *Está admirando cada vez más la pintura flamenca frente a Está admirando cada vez más a su profesor de piano, ambas construcciones se forman con un verbo de afección (admirar); en este caso, consideraremos ambas secuencias como P-E y un sujeto-agente. Desde nuestro punto de vista, ambas oraciones son la suma de diferentes fases por las que pasa el sujeto: admirar 1 + admirar 2 + admirar 3... (Existe un 'progreso dinámico' asociado al sentimiento de admiración del tema [ \pm humano], de ahí, que podamos establecer una cierta semejanza con los temas incrementales.) A medida que pasa el tiempo, la afección sentida aumenta y la perífrasis de gerundio (coacción aspectual) da cuenta de esa progresión temporal que se establece entre ambos constituyentes. Por tanto, ambas oraciones podrían considerarse gramaticales ante la presencia de un evento durativo pese a que nosotros veríamos más legítima la construcción en presente simple pero hemos de tener en cuenta que la presencia de cuantificadores así como la delimitación temporal es posible en ambos casos (nótese que el acto de admirar puede dejar de darse). Decir, también, que si consideramos ambos predicados como P-I, la construcción perifrástica colapsaría la secuencia.

Por último, en (45), Ese tipo de argumentaciones *está implicando más contradicciones versus ?está necesitando más verificaciones, se nos presenta una oración agramatical y otra de dudosa aceptabilidad. El matiz entre ambas estriba en que el verbo implicar puede ser considerado como un predicado de individuo, es decir, si algo implica algo, lo implicará siempre (carácter [-perfectivo] y permanente de los estados, inespecificación temporal-aspectual). Como hemos explicado anteriormente, los P-I no son afines con la perífrasis que estamos estudiando en este punto. Con respecto a la tercera oración de (45), nosotros la consideraríamos agramatical, al igual que la segunda de (45), pues la argumentación dada para esta podría valer para este tercer ejemplo, pero en este caso la aparición del adverbio comparativo (más) salvaguardaría, quizás, su dudosa aceptabilidad.

Pues bien, revisados todos los ejemplos, podemos concluir que la distinción que se establece tradicionalmente entre los predicados de individuo (P-I) y los predicados de estadio (P-E) radica en un matiz cuya naturaleza es semántico-aspectual. En ciertos casos, según Kuroda (1972), la diferencia viene marcada pragmáticamente y, por ello, unas veces entendemos que lo que se predica es una propiedad o caracterización del sujeto, pero en otras lo que percibimos es que el sujeto participa en un evento situado en una circunstancia espacio-temporal concreta. 
En numerosas ocasiones, se pueden analizar ciertos comportamientos sintácticos que atestiguan el carácter etiquetado como P-E, por ejemplo, ante la perífrasis progresiva o bien, los contextos que contienen información aspectual. Asimismo, y aunque no aparezca ningún ejemplo de este tipo, las cláusulas de imperativo dan cuentan del valor P-E de las citadas construcciones.

Respecto a la telicidad/atelicidad existente en las entradas léxicas de los verbos, podemos concluir que los predicados acotados (telos marcado) señalan la telicidad del evento y, por lo tanto, su estatus de P-E. Por el contrario, frente a estados no acotados, nos encontramos ante el efecto contrario, la atelicidad, y por ello, ante P-I.

Cuando estamos frente a un P-I, este automáticamente rechaza sintagmas temporales en cualquiera de sus construcciones sintácticas por su carácter atélico. El sintagma temporal durante un mes convierte esta oración en agramatical porque confiere valor télico a la oración, algo que rechazan totalmente los P-I:

(46) *Es alto durante un mes.

La estructura subeventiva viene marcada léxicamente (primitivos léxicos) por ciertos rasgos como son [ \pm dinámico], [ \pm télico], [ \pm homogéneo], etcétera, lo que dota a las construcciones de un carácter permanente (P-I) o bien de un carácter transitorio (P-E): a menor dinamismo, menor telicidad y mayor homogeneidad, mayor estatividad (estados, P-I); a mayor dinamismo, menor estatividad (eventualidades, P-E, por ejemplo, las actividades). Con respecto a la estatividad, esta puede ser considerada como una propiedad que es competencia del léxico.

En algunos casos, se puede observar un tipo de coerción denominada coacción aspectual (compete al nivel sintáctico) con la perífrasis estar + gerundio. Veamos un ejemplo:

(47) Tomás está saliendo ahora mismo de la oficina. (predicado de logro que se reinterpreta como predicado atélico)

Normalmente, el verbo estar coacciona (o recategoriza) un P-I y lo convierte en P-E (con la correspondiente transformación semántica): Eres muy guapo (P-I) / (Hoy) Estás muy guapo. (P-E).

\subsection{Aspecto y agentividad}

Tras observar los siguientes pares de oraciones, ¿̇cuáles son los contrastes de (a)gramaticalidad y/o (in)aceptabilidad teniendo en cuenta los aspectos siguientes: distinción P-I/P-E, categoría de aspecto léxico, rasgos de agentividad y control, factores de coacción aspectual, etcétera? Compárese todo ello con datos análogos de pares mínimos y contextos similares extendidos (con adjuntos):

(48) ¡Ten paciencia!/Está teniendo paciencia.

(49) *¿'Ten anginas!/*?Está teniendo anginas.

(50) *iTen problemas!/Está teniendo problemas. 
En el caso (48), estamos ante un verbo cuyo sujeto es agentivo (tener paciencia). Por esta razón, es posible su aparición en construcciones imperativas. Sin embargo, en Está teniendo paciencia estamos ante la combinación de la perífrasis de gerundio + predicado estativo. Habitualmente, esta circunstancia conduce a secuencias agramaticales salvo en los casos en los que el predicado de estadio resulte dinamizado, es decir, que adquiera el rasgo [+dinámico] porque tener paciencia se ha reinterpretado como un P-E.

En (49) y (50), *iTen anginas! y *iTen problemas!, vemos dos oraciones agramaticales pues no admiten un sujeto agentivo que controle la acción que evidencia el verbo, lo que implica que no pueden formar parte de mandatos (imperativos). Según García Fernández (2011) "se trata de una incompatibilidad semántica y no de una imposibilidad morfológica".

En cuanto a la secuencia agramatical de (49), *?Está teniendo anginas, estamos ante el verbo tener anginas, que se puede interpretar como un P-I (similar a tener los ojos negros). Tener anginas es lo mismo que decir que 'un sujeto posee amígdalas' por lo que su conjugación en gerundio resultaría agramatical. Ahora bien, si tener anginas se interpreta como 'estar enfermo de anginas', estaríamos ante un P-E, pues se presenta como una enfermedad de duración temporal indeterminada y que se da en el presente.

En (50), Está teniendo problemas es un predicado de estadio (P-E), evento temporal cuya perífrasis indica que los problemas se están produciendo en el momento de la enunciación y se extienden en el tiempo, pero no sabemos exactamente cuánto. Por ello, consideramos lícita la construcción sintáctica en la que aparece.

\section{Conclusiones}

Este trabajo ha intentado arrojar cierta luz en cuanto a los fenómenos más recurrentes dentro del ámbito objeto de este estudio: las relaciones entre el léxico y la sintaxis. Tras estos análisis, vemos que existen argumentos a los que se les podría adjudicar más de un papel temático y viceversa, sintagmas nominales que podrían interpretarse al amparo de dos papeles temáticos, de ahí, que podamos apoyarnos en la idea de rechazo de los papeles temáticos tradicionales que defendía Jackendoff pues esto repercutiría en un menor enriquecimiento a nivel de la estructura conceptual. Pero, por otro lado, no podemos rechazar de plano otras corrientes pues, en ciertas ocasiones, necesitamos apoyarnos en ellas para argumentar ciertos fenómenos lingüísticos de modo que se codifiquen las explicaciones necesarias pero presentadas desde diferentes vertientes pero no por ello incompatibles. Por tanto, y a modo de conclusión, podríamos afirmar que estar de un lado o del otro (dicho de otro modo, ser lexicista o ser semantista) no es más que un rechazo subyacente a una teoría que, como sucede en todas las corrientes, posee puntos fuertes, pese a que también adolece de lagunas que, quizás, desde nuestro punto de vista, podrían ser cubiertas por aquellas teorías que, en un principio, no aceptamos.

"El equilibrio es la última meta”, Ricky Lankford. 


\section{O Bibliografía}

》Apresjan, Jurij Derenikowicz. 1973. “Regular polysemy”. Linguistics 142: 5-32.

"Bello, Andrés. 1981 [1847]. Gramática de la lengua castellana destinada al uso de los americanos. Edición de Ramón Trujillo. Santa Cruz de Tenerife: Instituto Universitario de Lingüística Andrés Bello.

" Bosque, Ignacio. 2016. "Sustantivo". En Enciclopedia de Lingüística Hispánica, editada por Javier Gutiérrez-Rexach, vol. 2, 111-123. Londres: Routledge.

" Bosque, Ignacio y Javier Gutiérrez-Rexach. 2011. "Léxico y sintaxis". En Fundamentos de sintaxis formal, 307-310. Madrid: Akal.

"Chierchia, Gennaro. 1989. "A semantics for unacussatives and its syntactic consequences”. Artículo inédito. U. de Cornell.

" De Miguel, Elena. 2009. “La teoría del lexicón generativo". En Panorama de la lexicología, editado por Elena De Miguel, 337-367. Barcelona: Ariel.

" Dowty, David. 1991. "Thematic protoroles and argument selection". Language 67: 547619.

" Fernández Leborans, María Jesús. 2014. “La operación de reflexivización”. Revista Española de Lingüística 2: 75-102.

"Fernández Leborans, María Jesús y Cristina Sánchez. 2011. "Las interpretaciones de 'mucho' (y cuantificadores afines)". En 60 problemas de gramática: dedicados a Ignacio Bosque, editado por María Victoria Escandel Vidal, Manuel Leonetti y Cristina Sánchez López, 77-82. Madrid: Akal.

" García Fernández, Luis. 2011. "Algunas observaciones sobre se aspectual”. En Estudios sobre perífrasis y aspecto, editado por Juan Cuartero Otal, Luis García Fernández y Carsten Sinner, 43-71. Munich : Peniope.

» Hale, Ken y Jay Keyser. 1986. “Some transitivity alternations in English”. En Lexicon Project Working Papers, editado por Ken Hale y Jay Keyser. MIT Press.

" Hale, Ken y Jay Keyser. 1993. "On Argument Structure and the Lexical Expression of Syntactic Relations". En A View from Building 20: Essays in Honor of Sylvain Bromberger, editado por Ken Hale y Jay Keyser, 53-109. Cambridge, MA: MIT Press.

" Jackendoff, Ray. 1983. Semantics and cognition. Cambridge: MIT Press.

" Jackendoff, Ray. 1987. "The status of thematic relations in linguistic theory”. Linguistic Inquiry 18.3: 369- 411.

» Jackendoff, Ray. 1990. Semantic structures. Cambridge, MA: MIT Press.

" Kuroda, Sige-Yuki. 1972. "Categorical and thetic judgments: Evidence from Japanese syntax". Foundations of Language 9: 1-37.

" Mendikoetxea, Amaya. 2000. "Relaciones de interficie: los verbos de cambio de estado". Cuadernos de Lingüística 7: 125-144.

》Mendikoetxea, Amaya. 2007. "En busca de los primitivos léxicos y su realización sintáctica: del léxico a la sintaxis y viceversa”. Lingüística teòrica: análisi i perspectives 2: 55-102.

"Mendikoetxea, Amaya. 2009. "Modelos formales". En Panorama de la Lexicología, editado por Elena De Miguel, 301-336. Barcelona: Ariel. 
"Perlmutter, David. 1978. "Impersonal passives and the unaccusative hypothesis". Proceedings of the 4th Annual Meeting of the Berkeley Linguistics Society, 157-189.

»Pustejovsky, James. 1995. The generative lexicon. Cambridge, MA: MIT Press.

»Rappaport Hovav, Malka y Beth Levin. 2002. "Change of argument projections of state verbs: implications for the theories of argument projections". Proceedings of the 28th. annual meeting of the Berkey Linguistics Society, 269-280.

» Reinhart, Tanya. 1997. "Syntactic effects of lexical operations: reflexives and unaccusatives”. En OTS working papers in Linguistics.

» Reinhart, Tanya y Tal Siloni. 2004. “Against the unaccusative analysis of reflexives”. En The unacussativity puzzle, editado por Artemis Alexiadou, Elena Anagnostopoulou y Emma Everaert, 159-180. Oxford: Oxford university Press.

» Sánchez López, Cristina. 2002. “Las construcciones con se: Estado de la cuestión”. En Las construcciones con se, editado por Cristina Sánchez López, 18-163. Madrid: Visor.

»Simoni, María Elena. 2005. "Una clase de verbos preposicionales en la interficie léxicosintaxis". Cuadernos de Lingüística del IUOG 12: 77-88.

» Sorace, Aantonella. 2000. “Gradience in auxiliary selection with intransitive verbs”. Language 76.4: 859-890.

» Tenny, Carol. 1992. “The aspectual interface hypothesis”. En Lexical matters, editado por Ivan Sag y Anna Szabolcsi, 1-27. Standford, CA: CSLI Publications.

» Uriagereka, Juan y Eduardo Raposo. 1995. "Two types of small clauses (Toward a syntax of theme/rheme relations)". En Small clauses (Syntax and Semantics 28), editado por Anna Cardinaletti y María Teresa Guasti, 179-206. New York: Academic Press.

»Vendler, Zeno. 1967. Linguistics in philosophy. Londres: Cornell University Press.

\section{Webgrafía}

» Real Academia de la Lengua Española. Fecha de consulta, 24 de marzo de 2016. http:// lema.rae.es/dpd/?key=pensar+en. 